\title{
molecules
}

ISSN 1420-3049

www.mdpi.com/journal/molecules

Article

\section{Green Biosynthesis of Silver Nanoparticles Using Callicarpa maingayi Stem Bark Extraction}

Kamyar Shameli ${ }^{1,2, *}$, Mansor Bin Ahmad ${ }^{1}$, Emad A. Jaffar Al-Mulla ${ }^{1,3}$, Nor Azowa Ibrahim ${ }^{1}$, Parvaneh Shabanzadeh $^{4}$, Abdolhossein Rustaiyan ${ }^{5}$, Yadollah Abdollahi ${ }^{6}$, Samira Bagheri ${ }^{7}$, Sanaz Abdolmohammadi ${ }^{1}$, Muhammad Sani Usman ${ }^{1}$ and Mohammed Zidan ${ }^{1}$

1 Department of Chemistry, Faculty of Science, Universiti Putra Malaysia, Serdang UPM 43400, Selangor, Malaysia; E-Mails: mansorahmad@gmail.com (M.B.A.); emadaalmulla@yahoo.com (E.A.J.A.-M.); norazowa@science.upm.edu.my (N.A.I.); s.abdolmohammadi@yahoo.com (S.A.); muhusma@yahoo.com (M.S.U.); zidanupm@gmail.com (M.Z.)

2 Materials and Energy Research Center, Karaj 317-798-3634, Iran

3 Department of Chemistry, College of Science, University of Kufa, B.O. Box 21, An-Najaf 54001, Iraq

4 Department of Chemical Engineering, Faculty of Engineering, Islamic Azad University, Malard Branch 316-915-3174, Iran; E-Mail: parvaneh.shabanzade@gmail.com

5 Department of Chemistry, Science and Research Branch, Islamic Azad University, Tehran 145-157-75, Iran; E-Mail: arustaiyan@yahoo.it

6 Advance Materials and Nanotechnology Laboratory, Institute of Malaysia Advance Technology, Serdang UPM 43400, Selangor, Malaysia; E-Mail: yadollahabdollahi@yahoo.com

7 Centre of Research in Nanotechnology and Catalysis (COMBICAT), IPS Building, University of Malaya, Kuala Lumpur 50603, Malaysia; E-Mail: samira6363@yahoo.com

* Author to whom correspondence should be addressed; E-Mail: kamyarshameli@gmail.com; Tel.: +601-7344-3492; Fax: +603-8946-6043.

Received: 8 June 2012; in revised form: 20 June 2012 / Accepted: 21 June 2012 /

Published: 16 July 2012

Abstract: Different biological methods are gaining recognition for the production of silver nanoparticles (Ag-NPs) due to their multiple applications. The use of plants in the green synthesis of nanoparticles emerges as a cost effective and eco-friendly approach. In this study the green biosynthesis of silver nanoparticles using Callicarpa maingayi stem bark extract has been reported. Characterizations of nanoparticles were done using different methods, which include; ultraviolet-visible spectroscopy (UV-Vis), powder X-ray diffraction (XRD), transmission electron microscopy (TEM), scanning electron microscopy (SEM), energy dispersive X-ray fluorescence (EDXF) spectrometry, zeta potential measurements 
and Fourier transform infrared (FT-IR) spectroscopy. UV-visible spectrum of the aqueous medium containing silver nanoparticles showed absorption peak at around $456 \mathrm{~nm}$. The TEM study showed that mean diameter and standard deviation for the formation of silver nanoparticles were $12.40 \pm 3.27 \mathrm{~nm}$. The XRD study showed that the particles are crystalline in nature, with a face centered cubic (fcc) structure. The most needed outcome of this work will be the development of value added products from Callicarpa maingayi for biomedical and nanotechnology based industries.

Keywords: biosynthesis; silver nanoparticles; Callicarpa maingayi; green synthesis; fourier transform infrared

\section{Introduction}

Nanoparticles are normally considered as particles with a maximum size of $100 \mathrm{~nm}$. They display completely novel or improved properties, which are quite different from those of larger particles. In the compared to the larger particles of the bulk material that they are composed of based on specific characteristics such as size, shape, distribution, and surface morphology [1]. Metal nanoparticles, such as $\mathrm{Ag}, \mathrm{Au}, \mathrm{Pt}$ and $\mathrm{Pd}$, are extensively applied in products that directly come in contact with the human body, such as household items like detergents, soaps, shampoos, cosmetic products, and toothpaste, and they also find applications in the pharmaceutical and medical area [2].

Silver nanoparticles (Ag-NPs) have definite properties. This may perhaps have numerous applications in the fields of dentistry, clothing, catalysis, mirrors, optics, photography, electronics and food industries [3]. Because of such broad variety of applications, wide ranges of different preparation methods have been developed. However, the developing methods of Ag-NPs preparation, must give preference to control size of Ag-NPs. Therefore, nanosilver with small particle size and devoid of aggregation between particles is favorable in this purpose.

There are several ways to reduce $\mathrm{Ag}^{+}$: Use of $\gamma$-rays [4], UV irradiation [5], heating and electrochemical reduction [6], application of reducing chemicals, such as hydrazine [7], sodium borohydride [8-10], polyethylene glycerol [11], $N, N$-dimethylformamide [12], glucose [13], ethylene glycol [14], formaldehyde [15], sodium in liquid ammonia, etc. [16]. However, there is still need for a more economic, commercially viable as well environmentally green synthesis route to synthesize Ag-NPs. The green synthesis of Ag-NPs involves three main steps, which must be evaluated based on green chemistry perspectives, including selection of solvent medium, reducing agent and nontoxic stabilizers for Ag-NPs [17].

The biosynthesis of nanoparticles, which represents a connection between biotechnology and nanotechnology, has received increasing consideration due to the growing need to develop environmentally friendly technologies for material syntheses. The search for appropriate biomaterials for the biosynthesis of nanoparticles continues through many different synthetic methods [18].

The biosynthetic method using plant extracts has received more attention than chemical and physical methods and even than the use of microbes. The method is suitable for nanoscale metal synthesis due to the absence of any requirement to maintain an aseptic environment [19]. The 
possibility of using plant materials for the synthesis of nanoscale metals was reported initially by Gardea-Torresdey et al. [20,21]. Later, the bioreduction of various metals to nanosize materials of various shapes, capable of meeting the requirements of diverse industrial applications, was extensively studied [22]. In continuation, Zargar et al. demonstrated the prospect of using Vitex Negundo L. leaf methanolic extract for the synthesis of the Ag-NPs at ambient conditions, without any additive protecting nanoparticles from aggregating, template shaping nanoparticles or accelerants [23].

In this study, the synthesis and characterization of Ag/Callicarpa maingayi by a green method is reported. The Ag-NPs were prepared using silver nitrate as silver precursor and Callicarpa maingayi stem bark methanolic extract as reducing agent and stabilizer.

\section{Results and Discussion}

Reduction of $\mathrm{Ag}^{+}$into Ag-NPs during exposure to Callicarpa maingayi stem bark extracts could be followed by the colour change. The fresh suspension of Callicarpa maingayi was yellowish-green in colour. However, after addition of $\mathrm{AgNO}_{3}$ and stirring for $48 \mathrm{~h}$ at room temperature, the emulsion turned dark brown. The colour changes in aqueous solutions are due to the surface plasmon resonance phenomenon (Figure 1a,b). The result obtained in this investigation is interesting because it can serve as a foundation in terms of identification of potential forest plants for synthesizing Ag-NPs.

Figure 1. Photograph of (a) Callicarpa maingayi and (b) Ag/Callicarpa maingayi emulsion after 48 h.

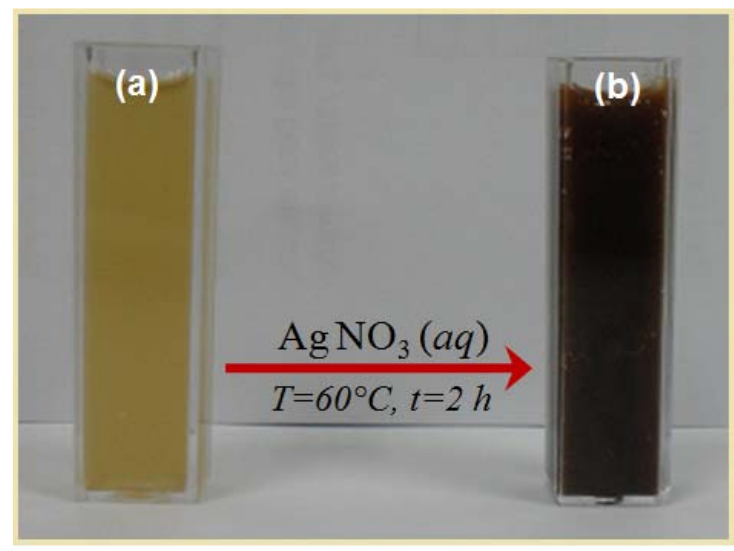

Callicarpa maingayi as an aldehyde can reduce silver ions to Ag-NPs. The possible chemical equations for preparing the Ag-NPs are:

$$
\begin{gathered}
\mathrm{Ag}^{+}(\mathrm{aq})+\text { Callicarpa maingayi } \stackrel{\text { Stirring in Room Temp. }}{\longrightarrow}[\mathrm{Ag}(\text { Callicarpa maingayi })]^{+} \\
{[\mathrm{Ag}(\text { Callicarring for } 48}
\end{gathered}
$$

After dispersion of silver ions in the Callicarpa maingayi aqueous solution matrix (Equation 1), the extract was reacted with the Ag to form [Ag (Callicarpa maingayi) $]^{+}$complex, which reacted with aldehyde groups in the molecular structure of the methanolic extract to form [Ag (Callicarpa maingayi)] due to the reduction of silver ions through the oxidation of aldehyde to carboxylic acid groups (Equation 2). 


\subsection{UV-Visible Spectroscopy Analysis}

The formation of Ag-NPs was followed by measuring the surface plasmon resonance (SPR) of the Callicarpa maingayi and Ag/Callicarpa maingayi emulsions over the wavelength range from 300-700 nm (Figure 2a,b). The SPR bands are influenced by the size, shape, morphology, composition and dielectric environment of the prepared nanoparticles [24,25]. Previous studies have shown that the spherical Ag-NPs contribute to the absorption bands at around 425-475 nm in the UV-visible spectra [26]. These absorption bands were assumed to correspond to the Ag-NPs extra fine nature, with relatively small size (less than $15 \mathrm{~nm}$ ). UV-Vis absorption spectra (Figure 2b) showed that the broad SPR band contained one peak at $456 \mathrm{~nm}$. This peak illustrates the presence of homogeneous distribution of hydrosol Ag-NPs after $48 \mathrm{~h}$ of stirring times [11,23].

Figure 2. UV-Vis absorption spectra of (a) Callicarpa maingayi and (b) Ag/Callicarpa maingayi emulsion after $48 \mathrm{~h}$.

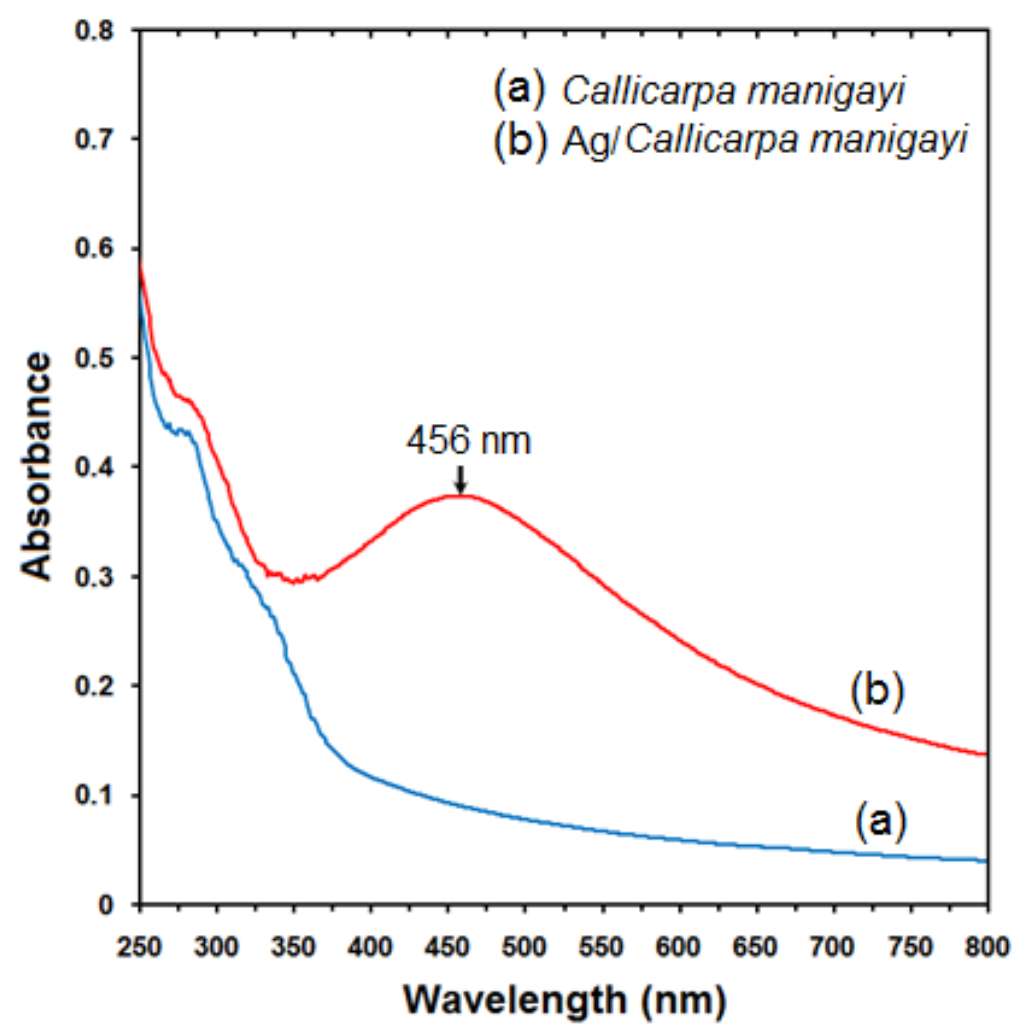

\subsection{Powder X-ray Diffraction}

Figure 3 shows the X-ray diffraction (XRD) patterns of vacuum-dried Ag-NPs synthesized using Callicarpa maingayi. The XRD patterns of Ag/Callicarpa maingayi indicated that the structure of Ag-NPs is face-centered cubic (fcc) [27]. In addition, all the Ag-NPs had a similar diffraction profile and XRD peaks at $2 \theta$ of $38.08^{\circ}, 44.36^{\circ}, 64.26^{\circ}$, and $77.30^{\circ}$ could be attributed to the $111,200,220$ and 311 crystallographic planes of the face-centered cubic (fcc) silver crystals, respectively [28]. The XRD pattern thus clearly illustrated that the Ag-NPs formed in this study are crystalline in nature. The main crystalline phase was silver and there was no obvious other phases as impurities were found in the XRD patterns (Ag XRD Ref. No. 01-087-0719). 
Figure 3. XRD patterns of Ag-NPs synthesized in Callicarpa maingayi for determination of Ag-NPs after $48 \mathrm{~h}$.

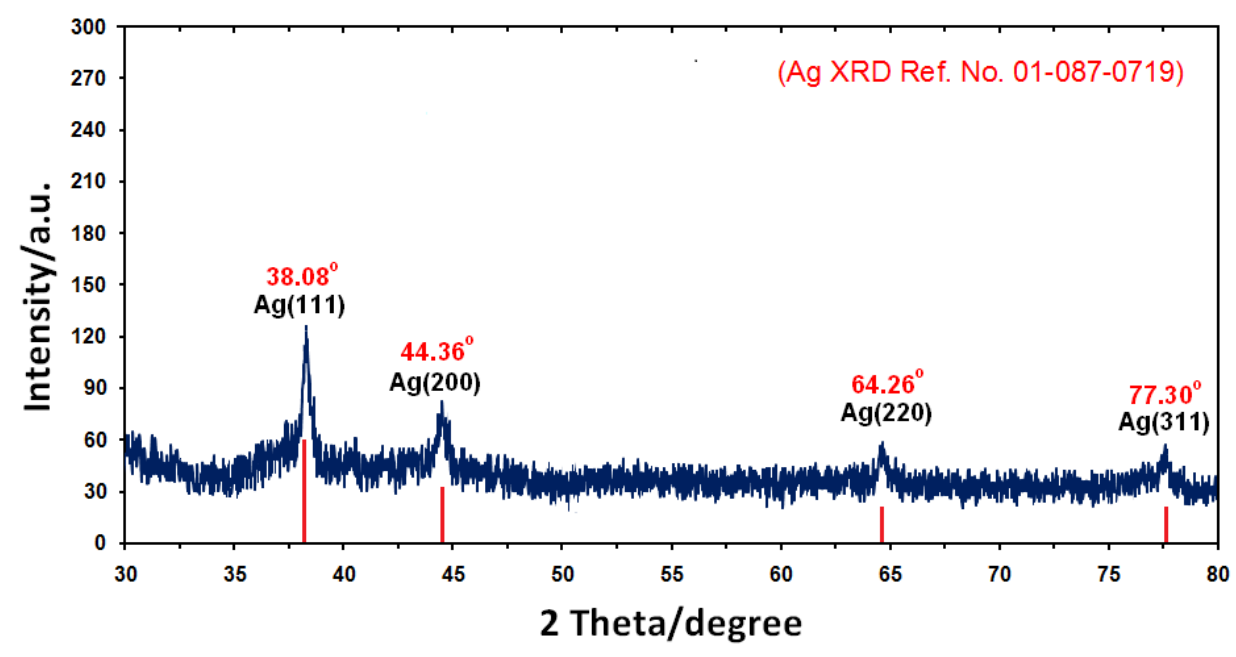

The average particle size of Ag-NPs can be calculated using the Debye-Scherrer Equation (3):

$$
n=\frac{K \lambda}{\beta \cos \theta}
$$

where $\mathrm{K}$ is the Scherrer constant with value from 0.9 to 1 (shape factor), where $\lambda$ is the $\mathrm{X}$-ray wavelength $(1.5418 \AA), \beta 1 / 2$ is the width of the XRD peak at half height and $\theta$ is the Bragg angle. From the Scherrer equation the average crystallite size of Ag-NPs for sample at $48 \mathrm{~h}$ of stirring time are found to be lower than $15 \mathrm{~nm}$ in size, which are also in line with the TEM results discussed later.

\subsection{Morphology Study}

For the transmission electron microscopy (TEM) study, a drop of the Ag-NPs solution synthesized by treating silver nitrate solution with Callicarpa maingayi was deposited onto a TEM copper grid. After drying, the grid was imaged using TEM. The TEM image and their size distribution are shown in Figure $4 a, b$, the result showed narrow particle size distributions, with diameters in the range of 9.13-15.67 nm. Moreover the mean diameter and standard deviation of Ag-NPs is $12.40 \pm 3.27 \mathrm{~nm}$.

The presence of one narrow distribution of Ag-NPs in TEM image are in accordance with the UV-Vis spectral study. Figure 4c,d show the Ag-NPs surrounded by the extract of Callicarpa maingayi. The dark points in this figure represent the large scale distribution of Ag-NPs. The Ag-NPs surrounded by Callicarpa maingayi extract is shown by TEM in Figure 4 and confirmed by FT-IR spectroscopy. The numbers of Ag-NPs counted for TEM image was around 566 at $48 \mathrm{~h}$ stirring time. These results confirms that extract of Callicarpa maingayi can effectively control shape and size of the Ag NPs. Figure 5a,b show the SEM image and EDXRF spectrum for the Ag-NPs in the Callicarpa maingayi extraction after $48 \mathrm{~h}$. 
Figure 4. TEM image and corresponding size distribution of Ag/Callicarpa maingayi after $48 \mathrm{~h}$.
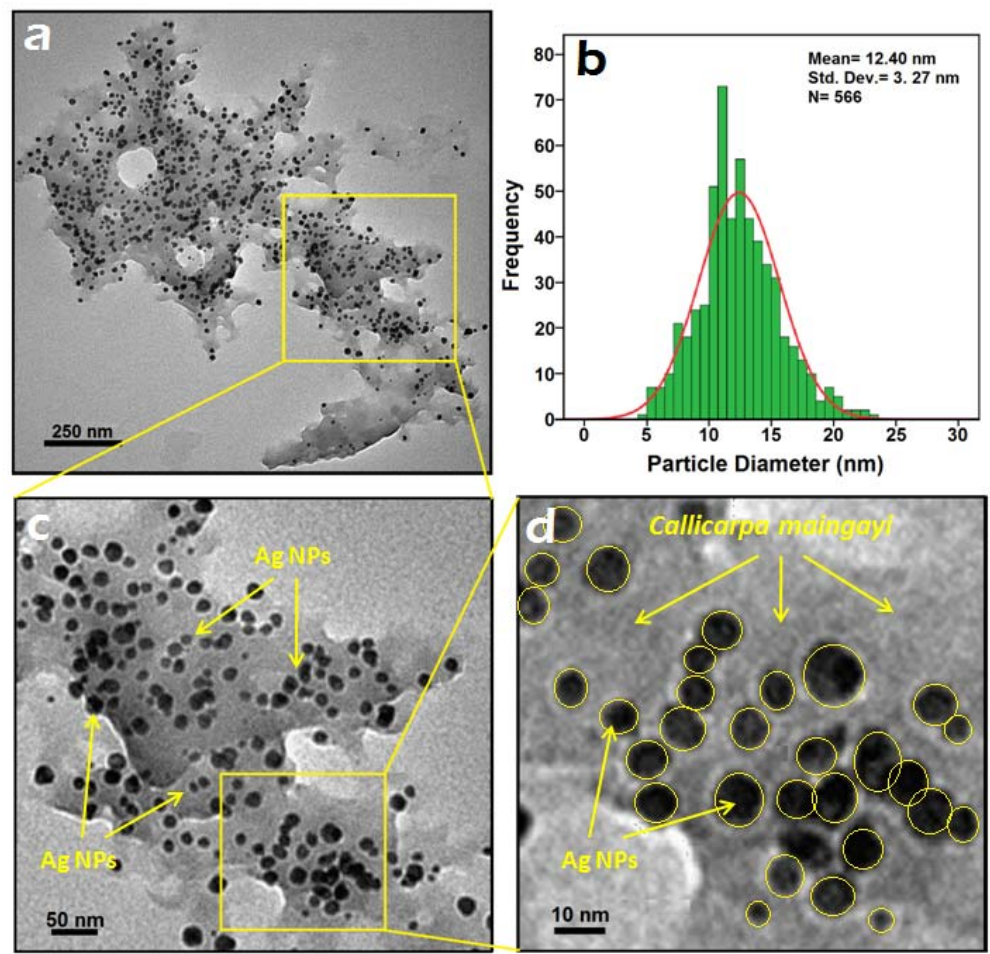

Figure 5. SEM image and EDXRF spectrum of Ag-NPs formed in Callicarpa maingayi Stem bark extraction after $48 \mathrm{~h}$.
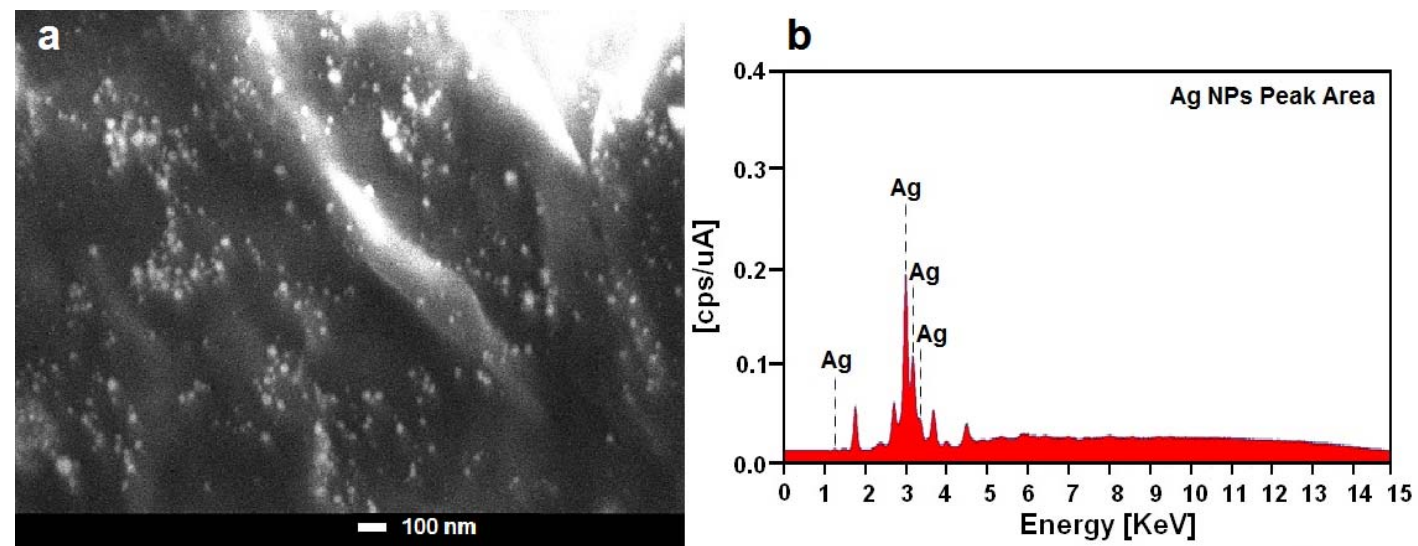

The external surfaces of Ag/Callicarpa maingayi gradually become more shiny, due to the presence of small size Ag-NPs (Figure 5a). A similar phenomenon was reported by Chandra et al. In the Figure 5b, the peaks around $1.3,3.1,3.3$ and $3.4 \mathrm{keV}$ are related to the silver elements in the Callicarpa maingayi [29].

Additionally, the EDXRF spectra for the Ag/Callicarpa maingayi confirmed the presence of Ag-NPs in the stem bark extraction without any impurity peaks. From EDAX spectrum, it is clear that Callicarpa maingayi has percent yield of $41.63 \%$ of Ag-NPs. The results indicate that the synthesized nanoparticles are composed of high purity Ag-NPs. 


\subsection{FT-IR Chemical Analysis}

The FT-IR spectra were recorded to identify the possible biomolecules responsible for the reduction of the $\mathrm{Ag}^{+}$ions and capping of the bioreduced Ag-NPs synthesized by the Callicarpa maingayi stem bark extract. The Callicarpa maingayi stem bark extract after complete bioreduction of $\mathrm{Ag}^{+}$was centrifuged at 18,000 rpm for $20 \mathrm{~min}$. to isolate the Ag-NPs from proteins and other compounds present in the solution. Figure 6A shows the FT-IR spectrum of pure Callicarpa maingayi stem bark extracts that did not contain $\mathrm{AgNO}_{3}$, where as Figure 6B shows the spectrum containing Ag-NPs after extract bioreduction with $\mathrm{AgNO}_{3}$. The spectrum in Figure 6A shows transmission peaks at 3317, 2927, $1579,1387,1252,1095,1037$ and at $413 \mathrm{~cm}^{-1}$. Similarly, transmission peaks for the stem bark extract containing Ag-NPs were obtained at 3379, 2923, 2602, 1960, 1703, 1581, 1358, 1203, 1049, 888, 788, 515 and $376 \mathrm{~cm}^{-1}$. Three absorption peaks located around 888, 788 and $1049 \mathrm{~cm}^{-1}$ can be assigned as the absorption peaks of $-\mathrm{C}-\mathrm{N}$ stretching vibrations of the amine, $-\mathrm{C}-\mathrm{O}-\mathrm{C}$ or $-\mathrm{C}-\mathrm{O}$ groups, respectively [30]. The bonds or functional groups such as $-\mathrm{C}-\mathrm{O}-\mathrm{C}-,-\mathrm{C}-\mathrm{O}$ and $-\mathrm{C}=\mathrm{C}-$ derived from heterocyclic compounds, e.g., alkaloid, or flavones, and the amide I bond derived from the proteins which are present in the stem bark extract are the capping ligands of the nanoparticles [31]. The broad and strong bands at 3379 to $2923 \mathrm{~cm}^{-1}$ were due to bonded hydroxyl (-OH) or amine groups $(-\mathrm{NH})$ and aliphatic $\mathrm{C}-\mathrm{H}$ of the Callicarpa maingayi stem bark extract, respectively. The peak at $1703 \mathrm{~cm}^{-1}$ is attributed to the carboxyl group $(-\mathrm{C}=\mathrm{O})$ stretching vibration. The adsorption at around $1358 \mathrm{~cm}^{-1}$ notably showed that $-\mathrm{NO}_{3}$ existed in residual amounts.

Figure 6. FT-IR spectra for the Callicarpa maingayi (A) and Ag/Callicarpa maingayi stem bark (B) after $48 \mathrm{~h}$ from biosynthesis reaction.

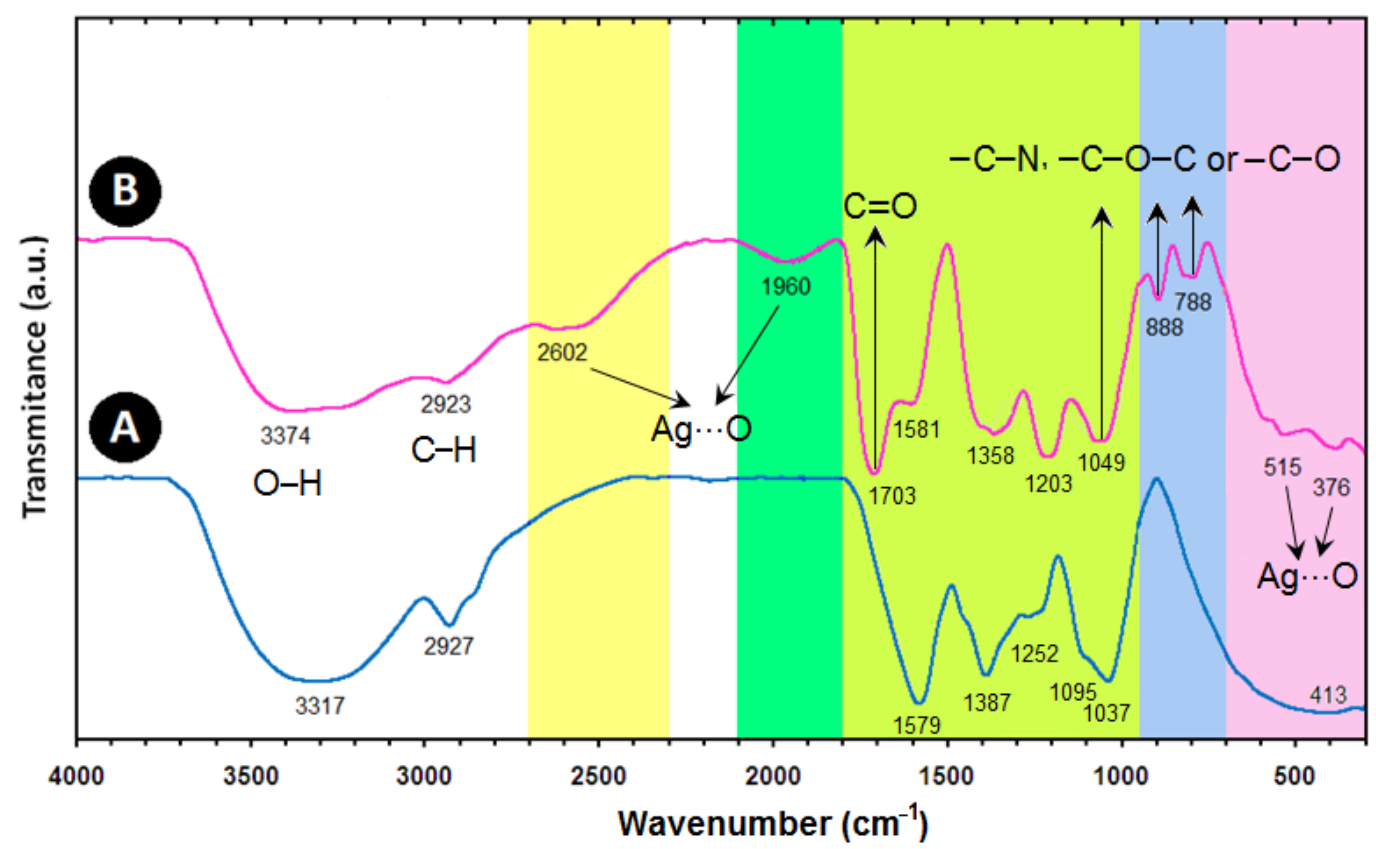

The peaks at 2602 and $1960 \mathrm{~cm}^{-1}$ which have high wavenumber and also 515 and $376 \mathrm{~cm}^{-1}$ in the low wavenumber, propose the presence of van der Waals forces of interaction between oxygen groups in protein structures and in Callicarpa maingayi extract on the surface of Ag-NPs (Ag...O) [11]. 
Therefore, the FT-IR results imply that the carboxyl $(-\mathrm{C}=\mathrm{O})$, hydroxyl $(-\mathrm{OH})$ and amine $(-\mathrm{NH})$ groups of Callicarpa maingayi stem bark extracts are mainly involved in fabrication of Ag-NPs.

\subsection{Zeta Potential Measurement}

As shown in Figure 7, the Ag-NPs obtained possess a positive zeta potential value. Zeta potential is an essential parameter for the characterization of stability in aqueous nanosuspensions. A minimum of $\pm 30 \mathrm{mV}$ zeta potential values is required for indication of stable nanosuspension [32]. At $48 \mathrm{~h}$ of stirring time, the zeta potential was equal to $35.5 \pm 3.7 \mathrm{mV}$. So, this result clearly indicated that the particles are fairly stable due to the electrostatic repulsion.

Figure 7. Zeta potential measurements for Ag/Callicarpa maingayi extract after $48 \mathrm{~h}$ of stirring time.

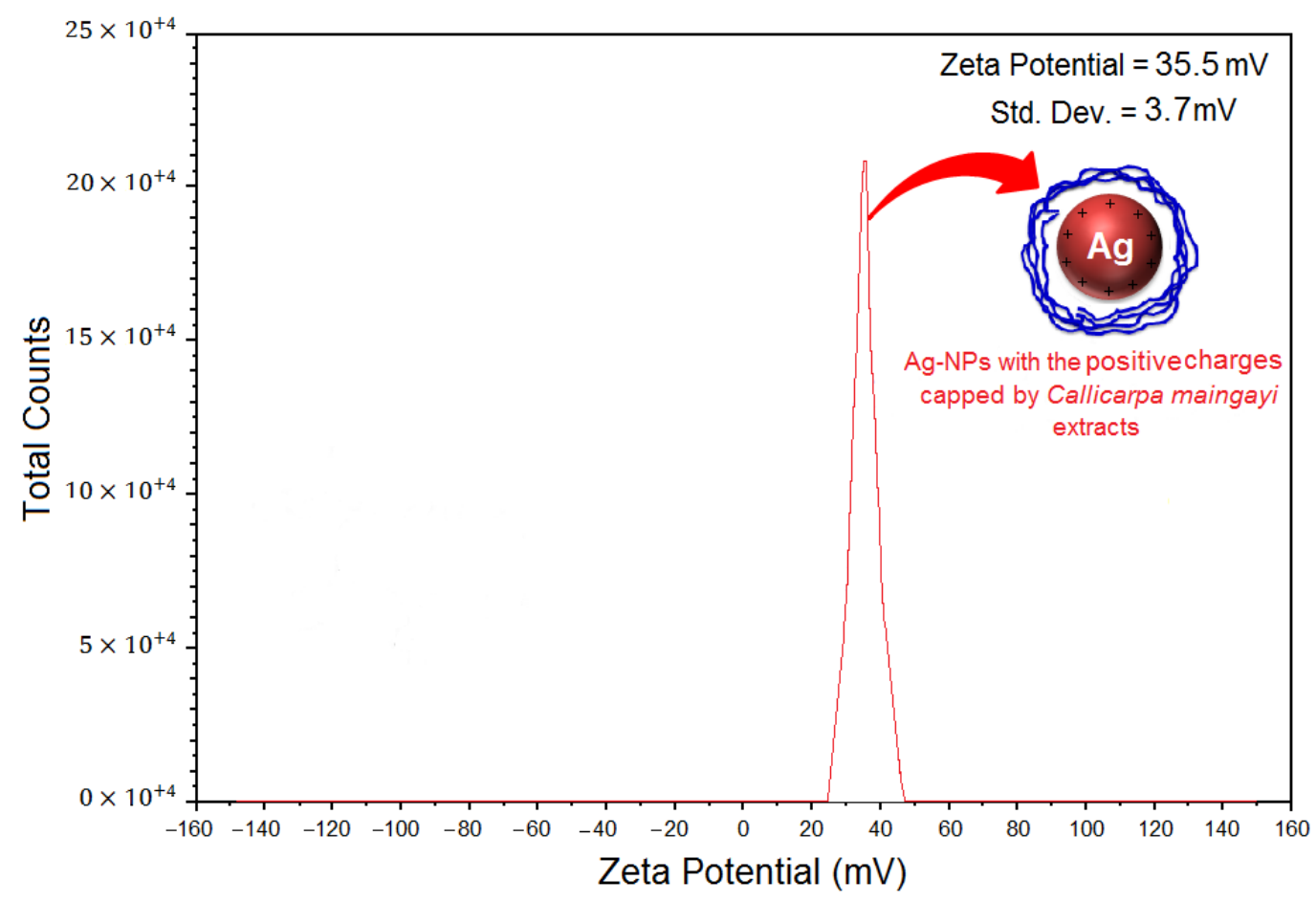

\section{Experimental}

\subsection{Materials and Method}

The stem bark of Callicarpa maingayi was collected from Terengganu, Malaysia. A voucher sample (No. SK 1542/08) has been deposited at the Herbarium of the Institute of Bioscience, Universiti Putra Malaysia (IBS-UPM). $\mathrm{AgNO}_{3}$ (99.98\%) was used as a silver precursor, and was provided by Merck (Frankfurter, Germany). All reagents in this effort were analytical grade and were used as received without further purification. All solutions were freshly prepared using double distilled water and kept in the dark to avoid any photochemical reactions. All glassware used in experimental procedures were cleaned in a fresh solution of $\mathrm{HNO}_{3} / \mathrm{HCl}(3: 1, \mathrm{v} / \mathrm{v})$, washed thoroughly with double distilled water, and dried before use. 


\subsection{Extraction Preparation}

Callicarpa maingayi plant and stem bark are shown in Figure 8a,b. Callicarpa maingayi stem bark was washed and dried in an oven dryer at $40{ }^{\circ} \mathrm{C}$ for $48 \mathrm{~h}$. The stem bark were then ground into powder, stored in dark glass bottles and kept at $-20{ }^{\circ} \mathrm{C}$ until further analyses Figure $7 \mathrm{c}$. The finely ground Callicarpa maingayi stem bark (20 g) was extracted with methanol/water (ratio 80:10 v/v) at room temperature for $72 \mathrm{~h}$ using a shaker (Protech, Terengganu, Malaysia).

Figure 8. Callicarpa maingayi Plant (a); Stem bark of Callicarpa maingayi (b); Stem bark powder of Callicarpa maingayi (c).
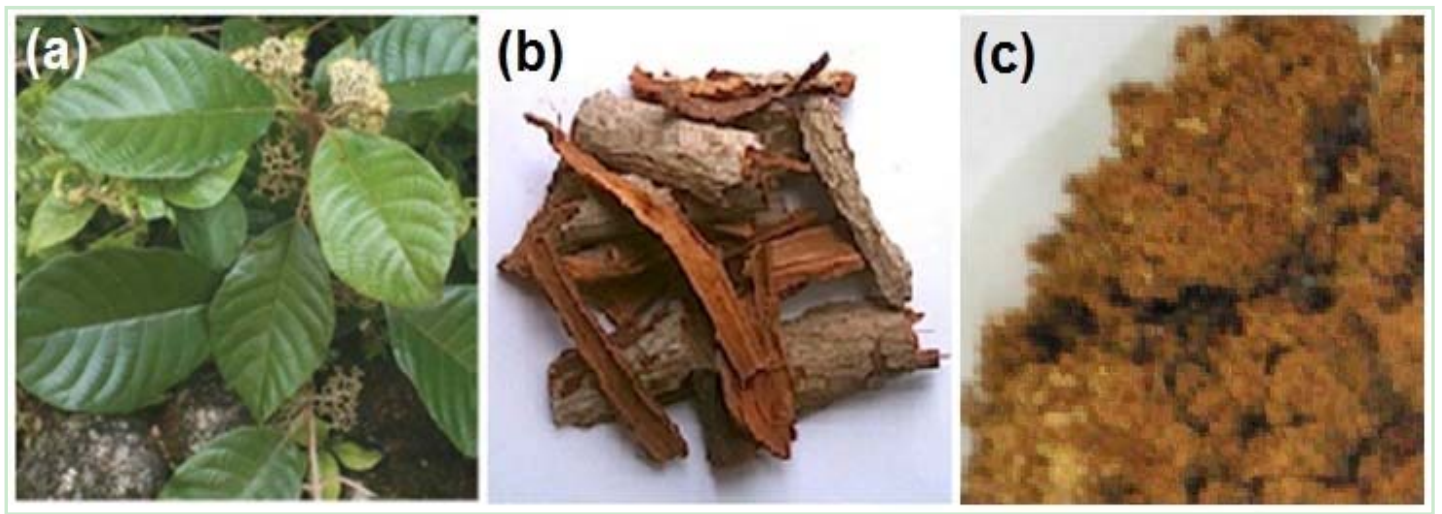

After filtration with Whitman filter paper No. 1 using a vacuum pump, the residue was re-extracted again with methanol solvent. The solvent was completely removed using a rotary vacuum evaporator (Buchi, Flavil, Switzerland) at $40{ }^{\circ} \mathrm{C}$. The concentrated extract was then kept in dark bottles at $4{ }^{\circ} \mathrm{C}$ until used.

\subsection{Synthesis of Ag/Callicarpa maingayi Emulsion}

Briefly, methanolic extract of stem bark Callicarpa maingayi $(1 \mathrm{~g})$ was added to distilled de-ionized water $(100 \mathrm{~mL})$ with vigorous stirring for $1 \mathrm{~h}$. A hundred milliliters of $\mathrm{Ag} \mathrm{NO}_{3}\left(1 \times 10^{-2} \mathrm{M}\right)$ was then added and mixed at room temperature $\left(25^{\circ} \mathrm{C}\right)$ for $48 \mathrm{~h}$. Ag-NPs were gradually obtained during the incubation period.

\subsection{Characterization Methods and Instruments}

The prepared Ag/Callicarpa maingayi were characterized by ultraviolet-visible spectroscopy (UV-Vis), X-ray diffraction (XRD), transmission electron microscopy (TEM), scanning electron microscopy (SEM), energy dispersive X-ray fluorescence spectrometry (EDXRF) and Fourier transform infrared (FT-IR) spectroscopy. The UV-visible spectra were recorded over the 300-700 nm range with a UV 1650 PC-Shimadzu B UV-visible spectrophotometer (Shimadzu. Osaka, Japan). The structures of the Ag-NPs produced were examined by X-ray diffraction (XRD-6000, Shimadzu). The XRD patterns were recorded at a scan speed of $4 \% \mathrm{~min}$. TEM observations were carried out on a H-7100 electron microscope (Hitachi, Tokyo, Japan), and the particle size distributions were determined using the UTHSCSA Image Tool version 3.00 program. SEM was performed using a 
Philips XL-30 instrument (Philips, Eindhoven, The Netherlands) to study the morphology of Ag/Callicarpa maingayi. The EDXRF was carried out on a DX-700HS spectrometer (Shimadzu). Meanwhile, the FT-IR spectra were recorded over the range of $400-4000 \mathrm{~cm}^{-1}$ using a FT-IR Series 100 , 1650 Perkin Elmer spectrophotometer (Los Angeles, California, USA). The zeta potential measurements were also performed using a Zetasizer Nano-ZS (Malvern Instruments, Worcestershire, UK).

\section{Conclusions}

The Ag-NPs with an average size of $12.40 \pm 3.27 \mathrm{~nm}$ and spherical in shapes were synthesized using methanolic stem bark extract of Callicarpa maingayi. The Ag-NPs were characterized by UV-visible, XRD, TEM, SEM, EDXRF, Zeta Potential and FT-IR spectrum. Biosynthesis of Ag-NPs using green resources like Callicarpa maingayi is a better alternative to chemical synthesis, since this green synthesis is pollutant free and eco-friendly. From the results obtained in this effort, one can affirm that Callicarpa maingayi stem bark can play an important role in the bioreduction and stabilization of silver ions to Ag-NPs.

\section{Acknowledgments}

The authors are grateful to the staff of the Department of Chemistry and Institute of Bioscience Universiti Putra Malaysia, for the laboratory facilities and technical assistance. As well as the assistance of S. M. Asiri for supplying Callicarpa maingayi stem bark extract is also appreciated.

\section{References}

1. Gurunathan, S.; Kalishwaralal, K.; Vaidyanathan, R.; Deepak, V.; Pandian, S.R.K.; Muniyandi, J. Biosynthesis, purification and characterization of silver nanoparticles using Escherichia coli. Colloid. Surf. B 2009, 74, 328-335.

2. Ankanna, S.; Prasad, T.N.V.K.V.; Elumalai, E.K.; Savithramma, N. Production of biogenic silver nanoparticles using Boswellia Ov Alifoliolata stem bark. Dig. J. Nanomater. Bios. 2010, 5, 369-372.

3. Rai, M.; Yadav, A.; Gade, A. Silver nanoparticles as a new generation of antimicrobials. Biotechnol. Adv. 2009, 27, 76-83.

4. Shameli, K.; Ahmad, M.B.; Wan Yunus, W.M.Z.; Ibrahim, N.A.; Gharayebi, Y.; Sedaghat, S. Synthesis of silver/montmorillonite nanocomposites using $\gamma$-irradiation. Int. J. Nanomed. 2010, 5 , 1067-1077.

5. Shameli, K.; Ahmad, M.B.; Wan Yunus, W.M.Z.; Rustaiyan, A.; Ibrahim, N.A.; Zargar, M.; Abdollahi, Y. Green synthesis of silver/montmorillonite/chitosan bionanocomposites using the UV-irradiation method and evaluation of antibacterial activity. Int. J. Nanomed. 2010, 5, 875-887.

6. Zhang, Y.; Chen, F.; Zhuang, J. Synthesis of silver nanoparticles via electrochemical reduction on compact zeolite film modified electrodes. Chem. Commun. 2002, 2814-2815.

7. Szczepanowicz, K.; Stefańska, J.; Socha, R.P. Preparation of silver nanoparticles via chemical reduction and their antimicrobial activity. Physicochem. Probl. Miner. Process. 2010, 45, 85-98. 
8. Shameli, K.; Ahmad, M.B.; Zargar, M.; Wan Yunus, W.M.Z.; Rustaiyan, A.; Ibrahim, N.A. Synthesis of silver nanoparticles in montmorillonite and their antibacterial behavior. Int. J. Nanomed. 2010, 6, 581-590.

9. Shameli, K.; Ahmad, M.B.; Wan Yunus, W.M.Z.; Ibrahim, N.A.; Synthesis and characterization of silver/talc nanocomposites using the wet chemical reduction method. Int. J. Nanomed. 2010, 5, 743-751.

10. Shameli, K.; Ahmad, M.B.; Zargar, M.; Wan Yunus, W.M.Z.; Ibrahim, N.A. Fabrication of silver nanoparticles doped in the zeolite framework and antibacterial activity. Int. J. Nanomed. 2011, 6, 331-341.

11. Shameli, K.; Ahmad, M.B.; Jazayeri, S.D.; Sedaghat, S.; Shabanzadeh, P.; Jahangirian, H.; Mahdavi, M.; Abdollahi, Y. Synthesis and characterization of polyethylene glycol mediated silver nanoparticles by the green method. Int. J. Mol. Sci. 2012, 13, 6639-6650.

12. Pastoriza Santos, I.; Liz Marzán, L.M. Formation and stabilization of silver nanoparticles through reduction by $N, N$-dimethylformamide. Langmuir 1999, 15, 948-951.

13. Ahmad, M.B.; Shameli, K.; Wan Yunus, W.M.Z.; Ibrahim, N.A. Synthesis and characterization of silver/clay/starch bionanocomposites by green method. Aust. J. Basic Appl. Sci. 2010, 4, 2158-2165.

14. Setua, P.; Pramanik, R.; Sarkar, S. Synthesis of silver nanoparticle inside the nonaqueous ethylene glycol reverse micelle and a comparative study to show the effect of the nanoparticle on the reverse micellar aggregates through solvation dynamics and rotational relaxation measurements. J. Phys. Chem. B 2010, 114, 7557-7564.

15. Praus, P.; Turicová, M.; Klementová, M. Preparation of silver-montmorillonite nanocomposites by reduction with formaldehyde and borohydride. J. Braz. Chem. Soc. 2009, 20, 1351-1357.

16. Sun, L.; Zhang, Z.; Dang, H. A novel method for preparation of silver nanoparticles. Mater. Lett. 2003, 57, 3874-3879.

17. Raveendran, P.; Fu, J.; Wallen, S.L. Completely "green" synthesis and stabilization of metal nanoparticles. J. Am. Chem. Soc. 2003, 125, 13940-13941.

18. Sathishkumar, M.; Sneha, K.; Won, S.W.; Cho, C.W.; Kim, S.; Yun, Y.S. Cinnamon zeylanicum bark extract and powder mediated green synthesis of nano-crystalline silver particles and its bactericidal activity. Colloid. Surf. B 2009, 73, 332-338.

19. Rai, A.; Singh, A.; Ahmad, A.; Sastry, M. Role of halide ions and temperature on the morphology of biologically synthesized gold nanotriangles. Langmuir 2006, 22, 736-741.

20. Gardea Torresdey, J.L.; Parsons, J.G.; Dokken, K.; Peralta Videa, J.R.; Troiani, H.; Santiago, P.; Jose Yacaman, M. Formation and growth of Au nanoparticles inside live alfalfa plants. Nano Lett. 2002, 2, 397-401.

21. Gardea Torresdey, J.L.; Gomez, E.; Peralta Videa, J.R.; Parsons, J.G.; Troiani, H.; Jose Yacaman, M. Alfalfa sprouts: A natural source for the synthesis of silver nanoparticles. Langmuir 2003, 19, 1357-1361.

22. Shankar, S.S.; Rai, A.; Ankamwar, B.; Singh, A.; Ahmad, A.; Sastry, M. Biological synthesis of triangular gold nanoprisms. Nat. Mater. 2004, 3, 482-488.

23. Zargar, M.; Hamid, A.A.; Bakar, F.A.; Shamsudin, M.N.; Shameli, K.; Jahanshiri, F.; Farahani, F. Green synthesis and antibacterial effect of silver nanoparticles using Vitex Negundo L. Molecules 2011, 16, 6667-6676. 
24. Kelly, K.L.; Coronado, E.; Zhao, L.L.; Schatz, G.C. The optical properties of metal nanoparticles: The influence of size, shape and dielectric environment. J. Phys. Chem. B 2003, 107, 668-677.

25. Stepanov, A.L. Optical Properties of Metal nanoparticles synthesized in a polymer by ion implantation: A review. Tech. Phys. 1997, 49, 143-153.

26. Stamplecoskie, K.G.; Scaiano, J.C. Light emitting diode can control the morphology and optical properties of silver nanoparticles. J. Am. Chem. Soc. 2010, 132, 1825-1827.

27. Ahmad, M.B.; Tay, M.Y.; Shameli, K.; Hussein, M.Z.; Lim, J.J. Green synthesis and characterization of silver/chitosan/polyethylene glycol nanocomposites without any reducing agent. Int. J. Mol. Sci. 2011, 12, 4872-4884.

28. Ahmad, M.B.; Lim, J.J.; Shameli, K.; Ibrahim, N.A.; Tay, M.Y. Synthesis of silver nanoparticles in chitosan, gelatin and chitosan/gelatin bionanocomposites by a chemical reducing agent and their characterization. Molecules 2011, 16, 7237-7248.

29. Shameli, K.; Ahmad, M.B.; Zargar, M.; Wan Yunus, W.M.Z.; Ibrahim, N.A.; Shabanzadeh, P.; Ghaffari-Moghadam, M. Synthesis and characterization of silver/montmorillonite/chitosan bionanocomposites by chemical reduction method and their antibacterial activity. Int. J. Nanomed. 2011, 6, 271-284.

30. Huang, J.; Li, Q.; Sun, D.; Lu, Y.; Su, Y.; Yang, X.; Wang, H.; Wang, Y.; Shao, W.; He, N.; Hong, J.; Chen, C. Biosynthesis of silver and gold nanoparticles by novel sundried Cinnamomum camphora leaf. Nanotechnology 2007, 18, 1-11.

31. Luo, L.; Yu, S.; Qian, S.; Zhou, T. Large-scale fabrication of flexible silver/cross-linked poly (vinyl alcohol) coaxial nanoscale by a facial solution approach. J. Am. Chem. Soc. 2005, 127, 2822-2823.

32. Jacobs, C.; Müller, R.H. Production and characterization of a budesonide nanosuspension for pulmonary administration. Pharm. Res. 2002, 19, 189-194.

Sample Availability: Samples of the different experiments are available from the authors.

(C) 2012 by the authors; licensee MDPI, Basel, Switzerland. This article is an open access article distributed under the terms and conditions of the Creative Commons Attribution license (http://creativecommons.org/licenses/by/3.0/). 